\title{
O ENCONTRO, OU AS IMAGENS SAEM DA BOCA
}

\author{
Júlia Vasconcelos Studart \\ UERJ
}

RESUMO: Esse texto é uma breve leitura crítica do pensamento de Raul Antelo, principalmente a partir do seu pequeno livro Tempos de Babel: destruição e anacronismo, publicado em 2017. Um gesto sempre em direção ao políitco, ou seja, ao não-aparentado. Ou seja, a tentativa de recompor uma leitura da teoria da destruição (Benjamin) para destruir a destruição, num pensamento que vem com e da história da arte provocando encontros com o meridiano: uma políitica do tempo.

PALAVRAS-CHAVE: Polííica; Tempo; Leitura crítica; Destruição.

\section{MEETING, OR IMAGES FLOW OUT OF THE MOUTH}

ABSTRACT: The essay traces some paths of the archiphilological procedure of the thinker Raúl Antelo, from the double ghost present, as he himself points out, in the archives: tautological illusion and belief. This double ghost is confronted by the thought of Raúl Antelo through the image of the an-archivist, which destabilizes the notion of autonomy in the arts.

KEYWORDS: Archiphilology; An-archivism; Phantasmagoria.

Júlia Vasconcelos Studart é professora da Escola de Letras da Universidade Federal do Estado do Rio de Janeiro. 


\title{
O ENCONTRO, OU AS IMAGENS SAEM DA BOCA
}

\author{
Júlia Vasconcelos Studart
}

\begin{abstract}
A história da arte é uma história de profecias.
Walter Benjamin, Estética e sociologia da arte

Trocando em miúdos, a matéria mordida e amassada é algo que, como as palavras, sai da boca e estabelece o regime do discurso, assim como o olhar fixa o regime das imagens e o coloca em funcionamento através das palavras. Ou seja, que através da fala essa coisa que, como a baba, sai da boca - nos colocamos, finalmente, atrás das imagens. Atrás do pensamento. Uma suspensão da razão. O neutro do sentido. ${ }^{1}$
\end{abstract}

\section{De CABEÇA PARA BAIXO}

No discurso de agradecimento ao prêmio Georg Büchner, em 22 de outubro de 1960, a que chamou de O Meridiano, Paul Celan, a certa altura, convida a atenção para algumas imagens que Büchner compôs a partir de Lenz (a novela inacabada). E não de Reinhold Lenz (1751 - 1792), o autor das Anotações sobre o teatro, que ele toma como "histórico", mas sim esse outro, o de Büchner, que se rearticula na capacidade de transformação e ubiquidade da arte, quando a arte é como uma marionete, mas também quando ela é objeto de uma conversa que tem lugar num quarto: “Uma conversa que - é esta a impressão com que se fica - poderia ser continuada indefinidamente, se nada se intrometesse nela. Mas há qualquer coisa que se intromete. E a arte volta a aparecer"2 diz ele.

Celan nos coloca diante de um problema, que ele toma como mutável, resistente e perene, ou seja, um problema eterno: o problema da arte, um problema com a arte. E Lenz, ou seja, Büchner, frente a esse problema com a arte, usa-a e faz dela uma contra-palavra. Diante de um pensamento como o de Büchner, esta parece ser a questão, nos colocamos também diante de uma imagem que sai da boca e se arreganha em "linhas inesquecíveis sobre 'a vida

\footnotetext{
${ }^{1}$ ANTELO, Raúl. Atrás das imagens. Fernando Lindote. Florianópolis: Fundação Franklin Cascaes / CESUSC, 2008, p. 71.

2 CELAN, Paul. Arte Poética: O Meridiano e outros textos. Trad. João Barrento. Lisboa: Cotovia, 1996, p. 41.
} 
das mais ínfimas criaturas, os 'estremecimentos', as 'alusões', o 'jogo expressivo tão sutil que mal se dá por ele' - o natural e o criatural." ${ }^{3} \mathrm{~A}$ imagem que vem desse Lenz figural, como uma rememoração, completa Celan, é:

... mas às vezes era-Ihe desagradável não poder andar de cabeça para baixo. - É este o Lenz. [...] Quem anda de cabeça para baixo, minhas senhoras e meus senhores, quem anda de cabeça para baixo tem o céu por abismo debaixo de $\mathrm{si}^{4}{ }^{4}$

O ponto, para Paul Celan, é que toda arte, que ele insiste como poesia, é qualquer coisa que tome como sentido uma mudança na respiração, um desvio, mas também uma espécie de regresso a casa: andar de cabeça para baixo, ter um abismo debaixo de si. Estamos ainda diante de um TALVEZ, quando a arte continua a viver "na proximidade do aberto e da liberdade. E por fim na proximidade da utopia." 5 numa tentativa de encontrar-se com qualquer coisa, como a linguagem, entre imaterial e terrena, porém planetária e circular, é que Celan esboça um movimento possível: quando a linguagem cruza os trópicos (esta "coisa divertida", diz ele) e se alarga num encontro com um meridiano.

\section{UM ENCONTRO COM O MERIDIANO}

Em 2007, Raúl Antelo publicou um pequeno livro: Tempos de Babel - destruição e anacronismo (Lumme Editor, coleção Móbile). O lançamento ocorreu no dia 11 de outubro de 2007, num café no centro de Florianópolis (o Et Cetera Café), que ficava à Rua Osmar Cunha, n. 260, dentro de um projeto de conversa que acontecia uma vez por mês retomando algumas circunstâncias de um filme de Federico Fellini: o Projeto 8 e 1/2.

Lembro que depois de sua fala, durante a conversa, alguém da plateia o interpelou com uma questão: se este livro lançava seus textos e seu pensamento em outras possibilidades de mais acesso aos seus leitores. Como se houvesse ali, no pequeno livro, o desenho de uma outra linha: intersecção de superfície crítica e imaginação com um meridiano.

A sugestão que dirigiam a ele era que este seu livro estava mais perto de uma outra construção de sentidos, mesmo que ainda mantivesse o abismo abaixo de si e o quanto ainda é agradável mover o mundo de cabeça para baixo, mas agora num gesto que recomeçava - a partir dessa publicação a cumprir um percurso em direção a um outro desenvolvimento excursivo.

\footnotetext{
3 Ibidem, p. 48.

${ }^{4}$ Ibidem, p. 53.

5 Ibidem, p. 60.
} 
Lembro também que ele riu e, quase vermelho, armou uma nova cifra diante da questão recompondo-a numa imagem que está no tal livro para começar a tentar responder, de algum modo, ao que se propunha ali, desde a epígrafe de Didi-Huberman retirada de Diante do Tempo:

Para que serve a história da arte? Para muito pouco, se ela se satisfaz com classificar sabiamente objetos já conhecidos, já reconhecidos. Para muito mais, se ela consegue colocar o não-saber no centro de sua problemática e tornar essa problemática a antecipação, a abertura de um novo saber, de uma forma nova do saber, ou até mesmo da ação. ${ }^{6}$

A imagem armada por ele é: Walter Benjamin, enquanto escrevia Rua de Mão Única, lia O Circo, livro de Ramón Gómez de la Serna, escritor espanhol que viveu entre 1888 e 1963, e que foi muito incensado, segundo ele, "[...] pelos vanguardistas do Prata como o mais radical representante do novo."7 $\mathrm{E}$ completa que $O$ circo foi um livro que "[...] deixaria profundas marcas não só nos materiais colhidos por Benjamin para uma teoria da modernidade, mas também na linguagem mais apta para que pudesse empreender essa pesquisa." 8

É essa conversa aparentemente distraída e insuspeita que me leva, de vez, naquele momento, a um encontro com os textos de Raúl Antelo como se fossem, ao mesmo tempo, o meu encontro com o meridiano. Já havia feito dois cursos com ele na UFSC, no ano anterior, em 2006, recém chegada no programa de Mestrado, enfrentando sua biblioteca e bibliografia espantosas, mas até então não havia me detido muito em seus próprios textos porque eles me faziam levantar a cabeça muitas vezes e, de toda maneira, eram muito difíceis para mim, formada em categorias formuladas por uma teoria da modernidade linear e quase sempre ordenada por uma historiografia canônica, quase restritiva. Me dei conta ali, durante aquela fala mais solta que ele dizia - a de uma conversa que tem lugar num quarto e que há qualquer coisa que se intromete nela -, de como o seu procedimento se articula num modo de operação crítica que está também, como aventura e deriva, em suas aulas sempre muito abrangentes e deliciosamente excessivas, e que poderia ser algo como: quando um pensamento que vem da história da arte cruza os trópicos (esta "coisa divertida", como sugere (elan), esbarra e se alarga num encontro com o meridiano. Um pensamento com o limiar.

\footnotetext{
${ }^{6}$ Cf. Ibidem, p. 7.

${ }^{7}$ ANTELO, Raúl. Tempos de Babel: destruição e anacronismo. São Paulo: Lumme Editor, 2007, p. 15.

${ }^{8}$ Ibidem, p. 15-16.
} 
Este seu pequeno e forte Tempos de Babel - destruição e anacronismo, por exemplo, não só me leva a tocá-lo de algum modo e de vez, numa possibilidade para um encontro, como, me parece, é provocado a partir da leitura que ele faz da proposição do encontro. Primeiro, o encontro de Benjamin com o livro de Ramón: "não é o fato de ele ter feito algum tratado sobre o circo como 'símbolo' do sentimento de vida, mas chama-lhe a atenção que ele tenha reunido uma 'coleção de apontamentos que se ajusta à realidade como o fraque ao palhaço." 9

Num suplemento, ele diz que Benjamin destaca, portanto, na teoria do moderno, entre as vias coletivas e simultâneas de elaboração, que o belo não é um atributo do objeto mas um modo de funcionamento em um determinado contexto cultural, quando registra que o percurso de Ramón é pontuado pelas personagens que encontra no circo: o magnetizador, o ilusionista, o contorcionista, o trapezista, as amazonas etc. E cita, numa nota de rodapé fundamental, um trecho longo da conhecida resenha de Benjamin para o Die Literarische Welt (O Mundo Literário) sobre o livro de Ramón, como sempre faz nos obrigando a ler à margem, nos obrigando a ler às margens (basta ver as notas intensas do livro que trata do encontro-meridiano entre Marcel Duchamp e Maria Martins - e que a edição brasileira não nos facilita):

Benjamin destaca aliás que Ramón "é ainda melhor no detalhe (em cada um deles). Sobre a louça da cozinha e o guarda-roupa do mágico, a esteira que o elefante pisa, o banquinho, os blocos e tonéis que são escalados por animais vestidos, a almofada de veludo bordado sobre a qual a atleta se deita durante seu número, enfim, sobre o conjunto do inventário do circo suas notas dizem o mais importante, isto é, o que mais nossa fantasia engolir; na verdade, é um inventário do sonho desgastado. Não existe ainda nenhuma convenção intelectual que oriente as discussões sobre as coisas do circo. Seu público é tão respeitável quanto o de qualquer teatro ou sala de concertos. Isto porque no circo a realidade tem a palavra, não a aparência. É muito mais provável que um senhor peça o programa ao vizinho enquanto Hamlet apunhala Polônio do que no momento em que o acrobata executa seu duplo salto mortal. [...] O circo é talvez um parque natural sociológico, no qual se executa o jogo entre as castas dos senhores, composta de criadores de cavalo e domadores, e um dócil proletariado, a plebe dos palhaços e dos empregados de estrebaria ainda ingênua, sem força revolucionária. É um (talvez estranho) lugar da liberdade de classe. Mas é ainda um lugar da liberdade em outro sentido: com razão disse Serna, em um conhecido discurso realizado do trapézio em um circo de Milão, que a verdadeira liberdade dos povos seria antes de mais nada conquistada em um circo. A mim parece que há apenas duas profissões que naturalmente sejam fiadoras da liberdade, e nenhuma das que se possa

${ }^{9}$ Ibidem, p. 17. 
geralmente pensar. Certamente não as muito suspeitas irmãs misericordiosas [...] ou os pacifistas [...], mas os matemáticos e os palhaços: o mestre do pensamento abstrato e o mestre da natureza abstrata. A liberdade, garantida por suas assinaturas, seria a única na qual eu confiaria. Essa liberdade conquistada no grande circo seria também a liberdade no interior do mundo animal, aquela que o patronato roubou dos homens. Pois este é o segredo do sentimento especial com que cada um adentra o circo: no circo, o homem é um convidado do reino dos animais. Os animais selvagens estão apenas aparentemente sob a tutela dos domadores; as artes que eles representam são sua maneira de entreter e destruir o irmãozinho mais novo, aliás, a única coisa que podem fazer com ele. A gente do circo aprendeu com os animais." ${ }^{10}$

E isso, ele escreve, não só antecipa em muito o que Benjamin veio a fazer depois com Baudelaire, mas o que Benjamin fez com Franz Kafka ou Reiner Maria Rilke, por exemplo, ao lê-los num limiar entre a humanização do animal e a animalização do homem, o que também apareceria no ensaio sobre Karl Kraus dedicado a um de seus melhores amigos: Gustav Glück. E é isso também que leva o próprio Raúl a ler, depois, um segundo encontro: o do exilado Ramón com os artistas da vanguarda no Prata e, muito, com os desdobramentos do pensamento de Ramón em Jorge Luís Borges, Oliverio Girondo e, principalmente, nas experiências artísticas de Macedonio Fernandez ou de Norah Borges que, segundo ele, "no campo das imagens, por exemplo, também estava elaborando uma percepção do moderno muito semelhante a dele e, por tabela, à do próprio Benjamin." ${ }^{\prime 1}$

\section{O CIRCO PERIFÉRICO}

Se esse pequeno livro vem de um percurso que começa, como um gesto em direção ao político, ou seja, ao não-aparentado, no encontro de Walter Benjamin com $O$ circo de Ramón Gómez de la Serna, é possível pensar nos procedimentos excursivos de Raúl Antelo a partir também de um terceiro encontro: o de Benjamin com Gustav Glück, numa pergunta que ele elabora, "Quem é Gustav Glück?"

Gustav Glück, diz Raúl Antelo, é basicamente o modelo de Benjamin. “Não é nenhum escritor', esclarece Benjamin a um outro amigo, Gerhard Scholem. Glück não passa de um banqueiro, um 'mundano e excelente banqueiro', como o apresenta em carta a outro amigo comum, Alfred Cohn, antigo companheiro de estudos à época, empresário em Barcelona." ${ }^{12}$

\footnotetext{
10 Ibidem, p. 17-18.

11 Ibidem, p. 19.

12 Ibidem, p. 23.
} 
Quando fugiu da Europa e instalou-se em Buenos Aires, por volta de 1938, Glück, nos lembra Raúl, conseguiu aquilo que Benjamin só pôde desejar. Depois, tornou-se cidadão argentino, dirigiu o banco Roberts e criou também uma liga de resistência pró-austríaca. Da Liga surge a Junta de la Victoria, uma associação feminista anti-fascista, "[...] através da qual Glück captava recursos financeiros que eram, mais tarde, enviados por ele mesmo à frente de guerra." ${ }^{13}$ Raúl nos lembra que esta Junta era dirigida por Cora Ratto de Sadosky, uma professora de matemática e ativista de direitos humanos, fundadora da União Internacional de Mulheres, em Paris, e da revista Columna 10, e que nela militavam artistas como a escritora Maria Rosa Oliver, a fotógrafa Annemarie Heinrich, a psicanalista Mimi Langer e a líder política Catalina Guagnini. Havia socialites como Margot Portela de Parker, mas também cientistas como Telma Reca. Depois, a artista Silvina Ocampo (esposa de Adolfo Bioy Casares, e íntima colaborada de Borges) e, ainda, suplente da Junta de la Victoria, justamente Norah Borges de Torre. Ou seja, diz ele, "[...] é um rol, quase disparatado, do caráter destrutivo da modernidade periférica." ${ }^{14}$

O fato é que Raúl Antelo passa a recompor uma leitura da teoria da destruição de Benjamin - "um modelo expressionista de forças em confronto" que "sedimentam a experiência em ruptura"15 - como uma condição híbrida, ou como ele sugere, ibero-americana. Não custa lembrar que o caráter destrutivo, para Benjamin, se inscreve como um despejo para abrir espaço, arejar, rejuvenescer, não ter interesse em ser compreendido porque tolera a incompreensão até as últimas consequências, mas por isso mesmo não promove a fofoca (o mais mesquinho dos fenômenos pequeno-burgueses, justamente porque as pessoas não querem ser incompreendidas). O destruidor é aquele que reage a uma constelação de perigos para interferir na autêntica catástrofe: não apenas que as coisas mudem, mas no pasmo que elas continuem exatamente como estão.

A tentativa de ler a modernidade, enquanto destruição da destruição, para ele, está articulada com a América Latina, ou seja, com os trópicos, numa perspectiva anacrônica para ler a história da arte numa intersecção de superfície e imaginação, como um meridiano. E é nessa modernidade periférica que ainda encontra e rearma a leitura que Sérgio Milliet, em São Paulo, faz de Gustav Glück durante a guerra; cito: “[...] para Glück, a pintura já se encontrava, a

\footnotetext{
13 Ibidem, p. 35.

14 Ibidem, p. 37.

15 Ibidem, p. 25.
} 
partir do século XIV, totalmente emancipada da arquitetura." Duas coisas aí, anota, parecem lhe interessar muito: uma primeira, "a condição historicamente marginal do artista moderno" e, depois, "o conceito de margem como lugar de negociação dilacerada". ${ }^{16}$ E escreve tomando o lugar do artista moderno entre destrutor/modernizador:

Poderíamos, no entanto, propor uma outra política do tempo: a do anacronismo. Ela implicaria, ao mesmo tempo, a inequívoca singularidade do evento e a ambivalente pluralidade da rede, na qual, através de uma constelação, esse acontecimento, finalmente, amarra-se no plano simbólico. (...) a temporalização do anacronismo significa uma participação temporal na temporalidade, ou, em suma, uma hipertemporalização, infinita e potencializada do evento. Se o que define o anacronismo é, portanto, a con-temporização, o tempo-com, então, não é tempo per se o que define a história cultural. Aquilo que define o tempo é, pelo contrário, o COM, é a sua sintaxe ou composição, seu uso, sua política. ${ }^{17}$

E o mais interessante disso tudo é que é possível ler no teatro de gesto intenso desse livro-móbile de Raúl Antelo o quanto seu procedimento crítico tem a ver, então, com o subtítulo que dá ao livro: anacronismo e destruição. E isto numa tentativa de arejar, abrir caminhos, destruir a destruição, num pensamento que vem com e da história da arte provocando encontros com o meridiano. Ou seja, o que nos obriga a repensar, como ele mesmo sugere, mais de uma vez ou muitas vezes, nas imagens que saem da boca: entre a fala e a baba, uma política do tempo e "as alianças anacrônicas do crítico cultural". ${ }^{18}$

Por fim, uma pequena digressão:

Will Eisner, novelista gráfico, escreve que vizinhanças têm períodos de vida, mas que as casas em que moramos nos definem tanto quanto nossa origem nacional, que elas nos dão uma espécie de filiação vitalícia numa fraternidade que se mantém unida em nossa memória. A dedicatória que o Raúl me escreveu nesse dia 11 de outubro de 2007, sem data, remete a essa ideia delicada de Will Eisner: "para Júlia, com o afeto do vizinho - Raúl".

16 Ibidem, p. 55-57.

17 Ibidem, p. 58-60.

18 Ibidem, p. 60. 